\title{
The study of incidence of accessory foramen transversaria in the cervical vertebrae
}

\author{
${ }^{1}$ Dr. Nilima P. Patil, ${ }^{2}$ Dr S.S. Dhapate, ${ }^{3}$ Dr. Satish Porwal, ${ }^{4}$ Dr V.B. Bhagwat \\ ${ }^{1,3,4}$ Asst. prof Anatomy. S.R.T.R.G.M.C.,Ambajogai \\ ${ }^{2}$ prof.Anatomy S.R.T.R.G.M.C,Ambajogai
}

\begin{abstract}
:
Introduction: The cervical vertebrae are identified by the presence of the foramen transversarium in the transverse processes which carries the vertebral artery, vertebral veins and sympathetic nerves. This foramen is known to exhibit variations in their number, size, shape which may lead to various symptoms. Their etiology is related with the variation in the course of vertebral artery due to developmental reasons. The objective of the present study was to find the incidence of accessory foramina transversaria in the cervical spine.

Method: This study included 175 dried human cervical vertebrae. Among them 100 were typical cervical vertebrae and 75 were atypical cervical vertebrae. All cervical vertebrae were observed macroscopically for the presence of double foramina transversaria on both the side. The data was compiled and analyzed using Microsoft excels software.

Result: Out of 175 cervical vertebrae the double foramen transversarium was found in only 10 vertebrae. The incidence was calculated as 5.71\%. Among them unilateral duplication was found in 6 vertebrae (3.42\%) and bilateral duplication was found in 4 vertebrae $2.28 \%$

Conclusion: Thus unilateral double foramen transversarium was more common than the bilateral one. Also the accessory foramina were observed in the lower cervical vertebrae i.e. in C4, C5, C6, and C7. Further the accessory foramina were smaller as compared to the regular foramina.
\end{abstract}

\section{Introduction;}

The cervical vertebrae are identified by the presence of foramen transversarium in the transverse processes. This foramen is known for passage of vertebral artery, vertebral veins and sympathetic nerves. (1) These foramina are known to exhibit variations with respect to the shape and size and numbers under such circumstances the course of vertebral artery may be distorted. The variations in number and size of foramina transversaria of cervical spine may be one of the causes for complaints like headaches, migraine and fainting attacks, usually due to compression of the vertebral artery. (2). Their etiology may be related to the variations of the course of vertebral artey.and to developmental causes. (1) This type of anatomical variations are important to the radiologist in interpreting X-rays and CT -Scans and also to the surgeons during posterior cervical spine surgeries(3). In the scientific literature, most of the anatomical and clinical studies have concentrated on the course and variant origins of the vertebral artery. There are only a very few reports available on the morphology of the accessory transverse foramina and their incidence. This was the stimulus for us to undertake this investigation. The objective of the present study was to find the incidence of accessory foramina transversaria in the cervical spine. The foramina were morphologically analyzed with an emphasis on their embryological basis and surgical importance.

\section{Material and methods}

This study included 175 dried human cervical vertebrae.Among them 100 were typical cervical vertebrae and 75 were atypical cervical vertebrae. The age and sex of the bones was not known. All cervical vertebrae were observed macroscopically for the presence of double foramina transversaria on both the side. Vertebrae with double foramen transversaria were photographed and the data was compiled and analyzed using Microsoft excels software.

\section{Result}

Out of 175 cervical vertebrae the double foramen transversarium was found in only 10 vertebrae. The incidence was calculated as $5.71 \%$. Among them unilateral duplication was found in 6 vertebrae $(3.42 \%)$ and bilateral duplication was found in 4 vertebrae $(2.28 \%)$. Thus unilateral double foramen transversarium was more common than the bilateral one. Further the accessory foramina were smaller as compared to the regular foramina. 
Also the double foramina were observed in the lower cervical vertebrae i.e. in $\mathrm{C} 4, \mathrm{C} 5, \mathrm{C} 6$, and $\mathrm{C} 7$.Each vertebra showed at least one foramen transversarium on either side.

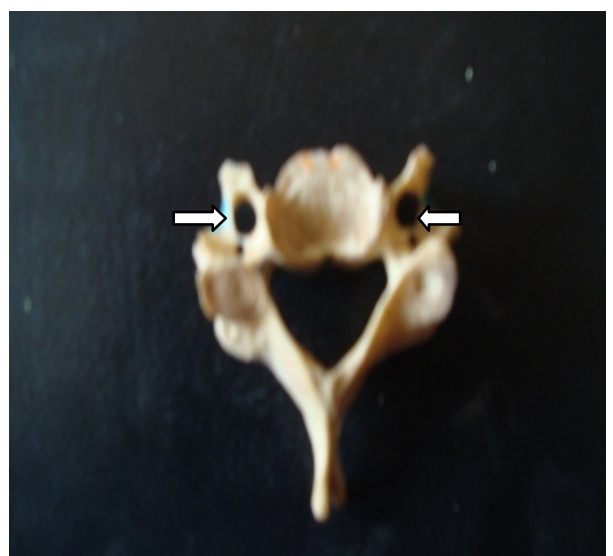

Fig; Cervical vertebra with bilateral accessory foramen transversaria

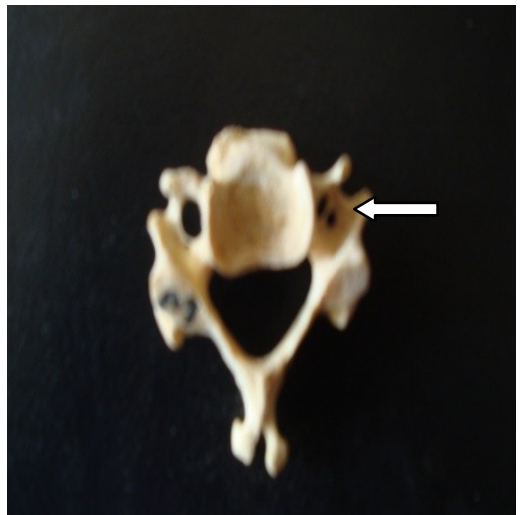

Fig; Cervical vertebra with right side (unilateral) accessory foramen transversaria

Table 1

\begin{tabular}{|l|l|l|l|l|l|}
\hline $\begin{array}{l}\text { Type of } \\
\text { vertebra }\end{array}$ & $\begin{array}{l}\text { No. of } \\
\text { vertebrae } \\
\text { observed }\end{array}$ & $\begin{array}{l}\text { Vertebrae with UL } \\
\text { Double foramen } \\
\text { transversarium }\end{array}$ & $\begin{array}{l}\text { Vertebrae with BL } \\
\text { Double foramen } \\
\text { transversarium }\end{array}$ & Total & \\
\hline C4 & 25 & 3 & & 3 & \\
\hline C5 & 25 & 2 & 1 & 3 & 3 \\
\hline C6 & 25 & 1 & 2 & 1 & \\
\hline C7 & 25 & & 1 & & \\
\hline & & & & & \\
\hline
\end{tabular}

Table no 1 show the incidence of double foramen transversarium in various vertebrae in the present study

\section{Discussion:}

The foramen transversarium is formed as the particular formation of the cervical transverse process. It is formed by the vestigial costal element fused to the body and true transverse process of the vertebra .(4). It is closed laterally by the costotransverse bar.(5)

The vertebral artery is developed from the fusion of the longitudinal anastomosis that link the cervical inter segmental arteries which branch off from the dorsal division of somatic inter segmental artery in neck region .These inter segmental arteries eventually regress except for the seventh artery which forms the proximal portion of the subclavian artery and beginning of the vertebral arteries.(6) Sim et al described that sometimes there occurs failure of the controlled regression of this portion of the primitive dorsal aorta along with the two inter segmental arteries 
which lead to the double origin and duplication of the vertebral arteries. The bilateral occurrence of these failures is the reason behind the bilateral duplication of the vertebral arteries.(7)

Since the vertebral vessels are the factors behind the formation of the foramen transversaria, it can be assumed that the variations in the presence and course of the vertebral arteries will manifest as variations of the foramen transversaria. In contrast variations in foramen transversaria can be useful in estimating variations of the vessels(5).

We found out 10 vertebrae out of 175 vertebrae having double foramina transversaria either unilateral (6) or bilateral (4). Further double foramen transversarium was found among lower cervical vertebrae.

The percentage of double foramen transversarium in our study was $5.71 \%$. In a study using 132 human cervical vertebrae conducted by Das Spirit(1) the incidence of double foramen transversaria was $1.5 \%$. Taitz et al reported the incidence of $7 \%$ among 480 vertebrae they studied.Incidence of accessory foramen transversaria in our study was nearer to that of Taitz et al.

As the vertebral vessels are important in the formation of foramen transversarium, it will be apparent that variation in the presence and course of vertebral vessels will result in the variation of foramen transversaria .

El Shaarwy et al observed that Accessory foramen transversaria were more common in lower cervical vertebrae mostly in C6.

Surgical anatomy and morphology is useful to the operating spine surgeon and radiologist in the interpretation of radiologic films and CT scans .Maintaining the vertebral artery is the important concern during cervical spine surgeries since minor lesions will lead to serious hemorrhage or even death(9). There are anatomical studies undertaken to minimize such accidental intra operative lesions of this artery(10). Compression of vertebral artery not only represented by neurological symptoms but also by hearing disturbances as this artery supplies the inner ear too.(11)

\section{References}

[1]. Das S, Suri R, Vijay K: Double foramen transversarium: An osteological study with clinical implications. International med j. 2005 12(02): 311-313.

[2]. Caovilla HH, Gananca MM, Munhoz MS. Silva ML: Sindrome cervical Quadros Clinicos Otoneurologicos Mais Comuns. Atheneu, Sao Paulo, 2000. 3(11), 95-100,

[3]. Kaya S, Yilmaz ND, Pusat S, Kural C, Kirik A, Izci Y: Double foramen transversarium variation in ancient byzantine cervical vertebrae: Preliminary report of an anthropological study. Turkish Neurosurgery. 2011, 21(4), 534-538.

[4]. MurlImanju BV, Prabhu LV, ShIlpa K, Rai R, Dhananjaya KVN, Jiji PJ. Turkish Neurosurgery. 2011, 21(3), 384-387

[5]. Taitz C, Nathan H, Arensburg B: Anatomical observations of the foramina transversaria.J NeurolNeurosurgPsychiatr 1978 . 41(1): 170176

[6]. Ionete C, Omojola MF: MR angiographic demonstration ofbilateral duplication of the extracranial vertebral artery: Unusual course and review of the literature. AJNR 27:1304-1306, 2006

[7]. Sim E, Vaccaro AR, Berzlanovich A, Thaler H, Ullrich CG:Fenestration of the extracranial vertebral artery: Review o the literature. Spine 26:139-142, 2001

[8]. El Shaarawy EAA, Sabry SM, El Gammaroy T, Nasr LE:Morphology and morphometry of the foramina transversaria of cervical vertebrae: A correlation with the position of the vertebral artery. Kasr El Aini Medical Journal [serial online] June 2010. Accessed December 10, 2010

[9]. Riew K: Microscope-assisted anterior cervical decompressionand plating techniques for multilevel cervical spondylosis.Operative Techniques in Orthopaedics 8:22-33, 1988

[10]. An HS, Gordin R, Renner K: Anatomic considerations for platescrew fixation of the cervical spine. Spine 16:548-551, 1991

[11]. Romanov VA, Miller LG, Gaevyı̌ MD: The effect of the vertebralnerve on circulation in the inner ear (cochlea). Biull Eksp Biol Med $75: 10-12,1973$ 